\title{
A simple flow-concentration modelling method for integrating water quality and water quantity in rivers
}

\author{
H Malan ${ }^{1 *}$, A Bath ${ }^{2}$, J Day ${ }^{1}$ and A Joubert ${ }^{3}$ \\ ${ }^{1}$ Freshwater Research Unit, Department of Zoology, University of Cape Town, Private Bag, Rondebosch 7700, South Africa \\ ${ }^{2}$ Water Corporation, Leederville, WA6007, Australia \\ ${ }^{3}$ Department of Statistical Science, University of Cape Town, Private Bag, Rondebosch 7700, South Africa
}

\begin{abstract}
As part of the determination of the ecological Reserve for rivers in South Africa (National Water Act, 1998), flow requirements are assessed for maintenance low flow, drought low flow and flood conditions. Since water quantity and water quality are often closely linked, it is necessary to ensure that in setting the recommended flow regime, the appropriate water quality will be attained. This paper presents a simple method (based on solute rating curves) for predicting the instream concentrations of chemical constituents that will arise from different flow regimes. The method uses monthly mean flow (discharge) at a given site plotted against monthly median concentration of each chemical constituent. This is carried out for both the reference condition (the natural, or least-impacted state) and for the present state. The flow-concentration relationships obtained are used to predict the expected monthly concentrations under the recommended flow regime. The computed concentrations can be compared with the reference condition and present state values to assess the degree of river modification. This paper outlines the modelling protocol to be followed, considers the limitations and assumptions inherent in the approach, and the application of the resultant information. It is concluded that the modelling method is a useful screening tool for identifying sites where, without reduction of pollution, the water quality component of the Reserve is unlikely to be attained under the recommended flow regime.
\end{abstract}

Keywords: water quality modelling, ecological Reserve, rating curves

\section{Introduction}

South African rivers are naturally variable in their patterns of flow, in addition to which abstraction of water, and regulation by means of impoundment, frequently modify the natural hydrological regime. It is well known that alterations in flow can lead to changes in water quality, although such changes are often complex and difficult to predict (Smith et al., 1996). Alterations in the concentrations of chemical constituents and in the values of physical variables present in the system can, in turn, exert a profound effect on the aquatic biota (Dallas and Day, 1993). Methods have been developed to calculate the quantity and timing of discharge required to maintain a given level of ecological functioning in a riverine ecosystem, commonly referred to in South Africa as the "environmental", or "instream flow requirement" (IFR) of a river (King and Louw, 1998; Hughes, 1999; 2001). The question of water quality is currently inadequately addressed within the process of calculating the IFR, however, and until recently, only qualitative predictions were made of the water quality likely to result from a proposed change in flow. Since efficient functioning of aquatic ecosystems is dependent not only on a suitable hydrological regime, but also on provision of water of a suitable quality (King and Louw, 1998), it is essential that quantitative predictive methods for water quality be incorporated in instream flow assessments. This reasoning is reflected in the National Water Act (No. 36 of 1998) which requires specification of both the amount (i.e. the volume and timing of

\footnotetext{
* To whom all correspondence should be addressed.

留 +2721 650 3872; fax: +2721 6503872 ;

e-mail: hmalan@botzoo.uct.ac.za

Received 30 August 2002; accepted in revised form 20 March 2003.
}

flow), and the quality of water that will maintain adequate biotic integrity and functioning of a river (DWAF, 1999). The water quality requirement prescribes, for a given resource protection level, the concentration of chemical constituents and values of physical variables that should not be exceeded. The National Water Act also calls for a system of classification of water resources, from those that are extremely impacted (class E or F) to those that are largely natural (class A). The degree of protection that is afforded to a river, or reach thereof, is dependent on the current state of the river and particularly on the class for which it will be managed (called the "ecological Reserve class"). The more protective the management class, the more stringent the water quality requirements. A system of assessment categories has also been devised for the common water quality variables (e.g. TDS, total inorganic nitrogen) ranging from A to F. Concentrations or values typical of un-impacted rivers are assigned to an "A" category. Increasing concentrations (in the case of chemical constituents) represent the boundary values that demarcate each category. At the time of writing this paper, the method for setting assessment categories for water quality within Reserve determinations is undergoing revision (DWAF, 2002).

This paper outlines a simple method (the "flow-concentration" or "Q-C" modelling method) developed to inter-relate water quality and water quantity. It has been developed to be used within the context of Reserve determinations, but may be useful in other situations where the effect of changing streamflow on water quality needs to be assessed. The steps were developed using data from actual Reserve assessments for several rivers in South Africa namely; the Palmiet River (Western Cape) and the Pienaars River (near Pretoria in Gauteng Province). The method was refined during the workshops that comprised the Olifants River Ecological Water Requirement Assessment Project (Malan, 2001) and the Breede River Basin 
i) Collate available data on water quality, point-sources of pollution, hydrological structures, hydrology, land use, topography, etc. Locate Instream Flow Requirement (IFR) sites.

ii) Identify the ecoregions through which the river flows. Derive reaches expected to exhibit uniform water quality.

iii) Correlate mean monthly discharge (stream flow) values and median monthly concentration values for each variable $(C)$ deemed to be of importance, at each IFR site.

a) For the reference condition (least impacted state).

b) For the present ecological state (possibly impacted).

iv) Examine the numerical relationship between flow and the concentration of the chemical constituent (C).

v) Estimate the predicted concentrations of $\mathrm{C}$ for the reference condition and present ecological state.

vi) Predict the monthly concentrations of $C$ expected under the recommended flow regime and calculate the $95 \%$ confidence around these predictions.

vii) Calculate the extent of deviation of the present ecological state values of $\mathrm{C}$ and the predicted concentration values from the reference condition.

viii) Assign the predicted assessment category for each month for each water quality variable and for each recommended flow scenario.

Figure 1

Summary of the steps in the flow-concentration (Q-C) modelling method

Project, and the results were used to predict the consequences with regard to water quality of the recommended flow regimes.

\section{The Q-C modelling method and its application to the Pienaars River}

The steps of the Q-C modelling method are summarised in Fig. 1. To highlight some of the issues involved, its application to the Pienaars River is described. For the sake of completeness all the steps have been shown, although the first two (in addition to the water quality section of the third step), are standard components of the water quality assessment for Reserve determinations (DWAF, 1999). Identification of water quality monitoring sites and potential sources of pollution, division of the river into ecoregions and (homogeneous) water quality reaches, and assessment of the water quality component of the Reserve are described in detail in Rossouw et al. (1999). A map of the study area, indicating the most significant features is shown in Fig. 2. The Q-C method was carried out for each water quality reach for which appropriate flow and water quality data were available, and each water quality variable was modelled separately. The results for total dissolved solids (TDS) in Water Quality Reach 1 (WQ1) of the Pienaars River are presented in this paper. Results for other chemical constituents and other reaches are documented in Malan and Day (2002a).

i) All available data on water quality, point sources of pollution, hydrological structures, hydrology, land use, topography, etc. were collated. The location of the IFR sites relative to Department of Water Affairs and Forestry's (DWAF) water quality monitoring stations,

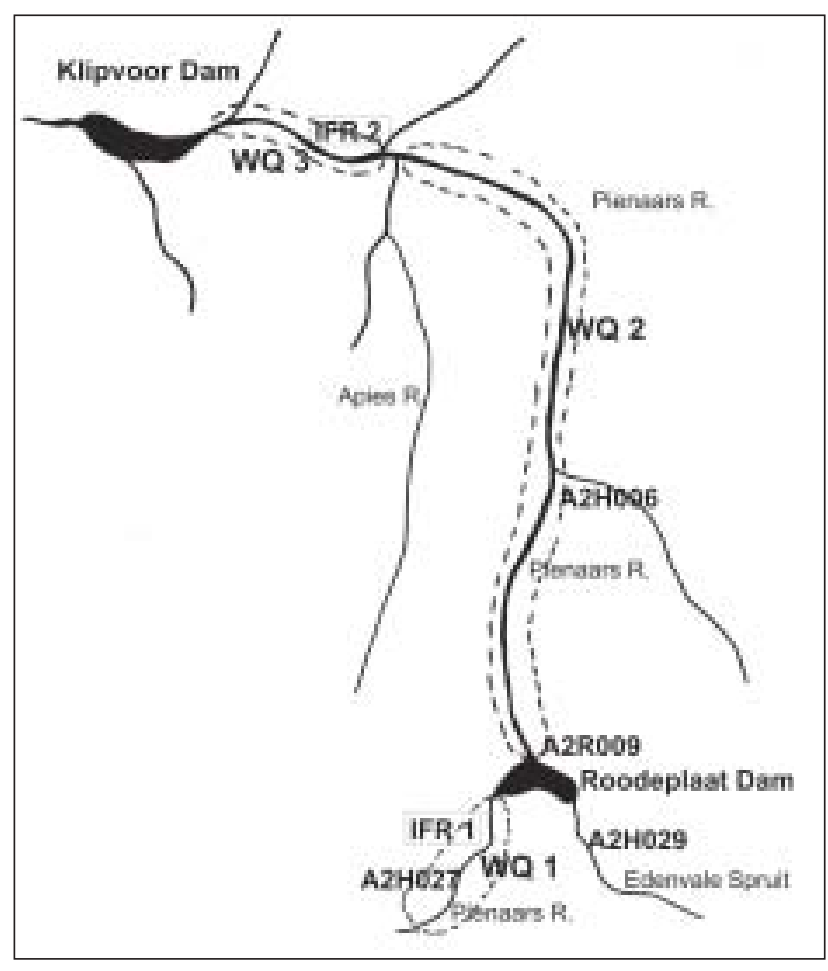

Figure 2

Schematic representation of the Pienaars River system showing the water quality reaches (WQ1, WQ2 and WQ3), significant hydrological features, Instream Flow Requirement

(IFR) sites and Department of Water Affairs and Forestry gauging sites/water quality monitoring stations (e.g. A2H029). Figure adapted from Rossouw et al. (1999).

flow-gauging sites, and any other significant hydrological features were identified.

A map indicating the above information was produced and is shown in Fig. 2.

ii) The different ecoregions through which the river flows were identified. Using this information, in conjunction with the location of impoundments, major tributaries and other significant hydrological features, the reaches within which water quality would be expected to be uniform (termed "water quality reaches") were delineated. This is discussed further in Rossouw et al. (1999).

iii) For each water quality reach in which an IFR site was situated, using the flow and water quality data from the nearest appropriate gauging and water quality monitoring station, mean monthly discharge values and median monthly concentration values for each water quality variable $(C)$ were derived and correlated for each month of the year. This was carried out for the reference condition (i.e. the natural orleast-impacted state) andfor the presentecological state (possibly impacted).

Tables were prepared recording mean monthly flow (for natural and present day), and median monthly values of each water quality variable for the reference condition (RCTDS) and present ecological state (PES TDS). The discharge and concentration data used to calculate these values were taken from the nearest appropriate DWAF gauging weir or water quality monitoring station. Table 1 shows TDS concentrations for Water Quality Reach 1 (WQ1). Median monthly values of water quality variables both for the reference condition and present state were obtained from Rossouw et al. (1999), and were 
TABLE 1

Measured stream flow and TDS data, as well as predicted values for Water Quality Reach 1 of the Pienaars River. Natural (reference condition) and current (present ecological state) discharge given as mean monthly values $\left(\mathrm{m}^{3} \times 10^{6}\right)$, TDS concentrations $(\mathrm{mg} / \mathrm{l})$ reported as monthly median values for the reference condition ([TDS] RC) and for the present state ([TDS] PES). Predicted reference and present state concentrations of TDS derived from the functions $y=-18 x+294$ and $y=-28 L n x+379$ respectively (where $x=m^{3} x 10^{6} / \mathrm{month}$ and $y=m g / l$ ).

\begin{tabular}{|l|c|c|c|c|c|c|c|c|c|c|c|c|c|}
\hline Month & Oct & Nov & Dec & Jan & Feb & Mar & Apr & May & June & July & Aug & Sept & Mean \\
\hline RC flow measured & 0.99 & 1.47 & 1.85 & 3.69 & 2.84 & 2.02 & 1.78 & 1.01 & 0.77 & 0.75 & 0.67 & 0.62 & $\mathbf{1 . 5 4}$ \\
RC [TDS] measured & 333 & 334 & 275 & 246 & 214 & 219 & 259 & 259 & 261 & 259 & 293 & 259 & $\mathbf{2 6 8}$ \\
RC [TDS] predicted & 277 & 269 & 262 & 230 & 245 & 259 & 263 & 277 & 281 & 281 & 283 & 284 & $\mathbf{2 6 8}$ \\
PES flow measured & 0.94 & 1.34 & 1.86 & 3.1 & 3.05 & 2.4 & 1.72 & 1.01 & 0.79 & 0.78 & 0.66 & 0.59 & $\mathbf{1 . 5 1}$ \\
PES [TDS] measured & 378 & 378 & 361 & 361 & 358 & 338 & 347 & 377 & 386 & 391 & 398 & 391 & $\mathbf{3 7 2}$ \\
PES [TDS] predicted & 381 & 371 & 362 & 348 & 348 & 355 & 364 & 379 & 386 & 386 & 391 & 394 & $\mathbf{3 7 2}$ \\
\hline
\end{tabular}

calculated using three years of data and a minimum of 60 data points. The table shows that under both natural and present conditions the highest flow occurs in the river during the summer months. Due to dilution of salts in the river during high-flow periods, the lowest annual concentrations of TDS are recorded at these times.

iv) The relationship between flow and concentration $(C)$ was then examined.

A regression line was drawn through the data points separately for the reference condition (RC) and for the present ecological state (PES). The "best fit" was selected using the relationship (linear, logarithmic, exponential or power) that yielded the highest value of the regression coefficient, $r^{2}$. Figure 3 shows a graph of TDS concentration plotted against flow for Water Quality Reach 1. It can be seen that the concentrations of TDS under the present ecological state are higher than under the reference condition, indicating that salinity is currently elevated in the river. The Q-C plot for the present state was best described by a logarithmic function $\left(r^{2}=0.7\right)$ whilst that of the reference condition was described by a linear function (Fig. 3). The value of $r^{2}$ for the reference condition is low $\left(r^{2}=0.2\right)$, since this value is below the critical value of $r^{2}=0.332$ (for 10 degrees of freedom and $\mathrm{p}=0.05$ ). This relationship was not used to predict future concentration, however, but merely to calculate percentage deviation from natural, and thus for this purpose it is considered to be acceptable by the authors.

v) The predicted concentrations of variable $C$ for the reference condition and present ecological state were then estimated.

The predicted values of the variable (C) in the reference condition and present state were estimated using the appropriate regression equation. All regression equations were transformed to linear equivalents and confidence intervals calculated using standard statistical formulae (Underhill, 1985). The 95\% confidence interval for the predicted present state values is shown in Fig. 3.

vi) The monthly concentrations expected under the recommended flow regimes and the $95 \%$ confidence interval around these predictions were calculated.

The technique for estimating the environmental flow requirement of rivers that is currently used in Reserve determinations is the Building Block Methodology (King and Louw, 1998; DWAF, 1999; King et al., 2000). In this methodology, the recommended flow regime is prescribed for each month of the year and is given for both normal hydrological years (i.e. maintenance low flows that will sustain the river in the required state) and for drought years (i.e. flows that will

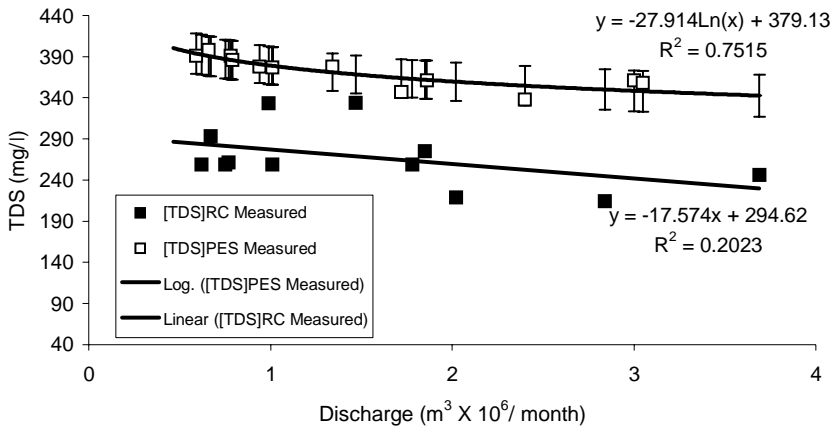

Figure 3

Q-C plot for TDS in Water Quality Reach 1 on the Pienaars

River. Measured reference condition (RC) and present ecological state (PES) concentrations of TDS are shown. Also shown are the regression lines exhibiting the highest $r^{2}$ value,

the equations describing these relationships and the 95\% confidence interval for the present ecological state.

ensure survival of critical species during periods of low rainfall (Louw et al., 2000). Using the regression equation describing the relationship between present-state concentration and flow, the predicted monthly concentration and $95 \%$ confidence interval of each water quality constituent under the recommended flow regimes was calculated. Table 2 shows the TDS concentrations predicted for Water Quality Reach 1 of the Pienaars River for each month of the year under both maintenance and drought low flows. Because TDS concentration at this site is negatively correlated with discharge, the concentrations predicted under drought flow are higher than for maintenance low flow. To simulate natural hydrological conditions in the river under the proposed flow regime, for both maintenance and drought conditions, the highest flows are recommended during the summer months. Consequently, the lowest TDS concentrations are predicted to occur during this period.

vii) The deviation of the existing (present ecological state) values of $C$, and the predicted concentrations of $C$, from the reference condition were calculated.

The predicted concentrations of the different water quality variables were compared with the concentrations in the reference condition and the difference calculated using the following:

Deviation from reference condition $=\frac{\left(\text { Predicted }[\mathrm{C}]-[\mathrm{C}]_{\mathrm{RC}}\right)}{[\mathrm{C}]_{\mathrm{RC}}}$ 


\section{TABLE2}

Monthly flow values $\left(\mathrm{m}^{3} \times 10^{6}\right.$ /month) for a recommended flow regime (maintenance and drought low flow) for Water Quality Reach 1 on the Pienaars River. The corresponding predicted monthly concentrations of TDS, \% deviation from reference condition (values given in Table 1), and assessment category are also shown. The mean annual value is given in the final column.

\begin{tabular}{|c|c|c|c|c|c|c|c|c|c|c|c|c|c|c|}
\hline Month & & Oct & Nov & Dec & Jan & Feb & Mar & Apr & May & June & July & Aug & Sept & Mean \\
\hline $\begin{array}{l}\text { Maintenance low flow } \\
\text { Drought low flow }\end{array}$ & 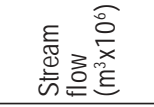 & $\begin{array}{l}\mathbf{1 . 0} \\
0.5\end{array}$ & $\begin{array}{l}\mathbf{1 . 3} \\
0.6\end{array}$ & $\begin{array}{l}\mathbf{1 . 5} \\
0.8\end{array}$ & $\begin{array}{l}\mathbf{3 . 0} \\
1.0\end{array}$ & $\begin{array}{l}2.2 \\
0.9\end{array}$ & $\begin{array}{l}\mathbf{1 . 8} \\
0.8\end{array}$ & $\begin{array}{l}\mathbf{1 . 5} \\
0.7\end{array}$ & $\begin{array}{l}\mathbf{1 . 0} \\
0.5\end{array}$ & $\begin{array}{l}\mathbf{0 . 7} \\
0.3\end{array}$ & $\begin{array}{l}\mathbf{0 . 7} \\
0.2\end{array}$ & $\begin{array}{l}\mathbf{0 . 6} \\
0.1\end{array}$ & $\begin{array}{l}\mathbf{0 . 5} \\
0.2\end{array}$ & $\begin{array}{l}1.3 \\
0.5\end{array}$ \\
\hline $\begin{array}{l}\text { Maintenance low flow } \\
\text { Drought low flow }\end{array}$ & 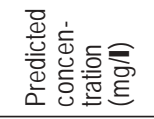 & $\begin{array}{l}379 \\
405\end{array}$ & $\begin{array}{l}372 \\
393\end{array}$ & $\begin{array}{l}368 \\
385\end{array}$ & $\begin{array}{l}\mathbf{3 4 8} \\
379\end{array}$ & $\begin{array}{l}357 \\
382\end{array}$ & $\begin{array}{l}\mathbf{3 6 3} \\
385\end{array}$ & $\begin{array}{l}\mathbf{3 6 7} \\
389\end{array}$ & $\begin{array}{l}379 \\
398\end{array}$ & $\begin{array}{l}389 \\
413\end{array}$ & $\begin{array}{l}389 \\
424\end{array}$ & $\begin{array}{l}394 \\
443\end{array}$ & $\begin{array}{l}397 \\
424\end{array}$ & $\begin{array}{l}375 \\
402\end{array}$ \\
\hline $\begin{array}{l}\text { Present Ecological State } \\
\text { Maintenance low flow } \\
\text { Drought low flow }\end{array}$ & 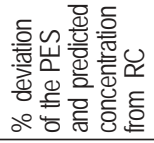 & $\begin{array}{l}37 \\
37 \\
46\end{array}$ & $\begin{array}{l}38 \\
\mathbf{3 8} \\
46\end{array}$ & $\begin{array}{l}38 \\
\mathbf{4 0} \\
47\end{array}$ & $\begin{array}{l}52 \\
\mathbf{5 2} \\
65\end{array}$ & $\begin{array}{l}42 \\
46 \\
56\end{array}$ & $\begin{array}{l}37 \\
40 \\
49\end{array}$ & $\begin{array}{l}38 \\
\mathbf{3 9} \\
48\end{array}$ & $\begin{array}{l}37 \\
37 \\
44\end{array}$ & $\begin{array}{l}37 \\
38 \\
47\end{array}$ & $\begin{array}{l}37 \\
38 \\
51\end{array}$ & $\begin{array}{l}38 \\
39 \\
57\end{array}$ & $\begin{array}{l}39 \\
40 \\
49\end{array}$ & $\begin{array}{l}39 \\
40 \\
50\end{array}$ \\
\hline $\begin{array}{l}\text { Present Ecological State } \\
\text { Maintenance low flow } \\
\text { Drought low flow }\end{array}$ & 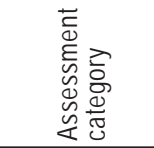 & $\begin{array}{c}\text { D } \\
\text { D } \\
\text { E/F }\end{array}$ & $\begin{array}{c}\text { D } \\
\text { D } \\
\text { E/F }\end{array}$ & $\begin{array}{l}\text { D } \\
\text { E/F } \\
\text { E/F }\end{array}$ & $\begin{array}{l}\mathbf{E} / \mathbf{F} \\
\mathbf{E} / \mathbf{F} \\
\mathbf{E} / \mathbf{F}\end{array}$ & $\begin{array}{l}\mathbf{E} / \mathbf{F} \\
\mathbf{E} / \mathbf{F} \\
\mathbf{E} / \mathbf{F}\end{array}$ & $\begin{array}{l}\text { D } \\
\text { E/F } \\
\text { E/F }\end{array}$ & $\begin{array}{c}\text { D } \\
\text { D } \\
\text { E/F }\end{array}$ & $\begin{array}{c}\text { D } \\
\text { D } \\
\text { E/F }\end{array}$ & $\begin{array}{c}\text { D } \\
\text { D } \\
\text { E/F }\end{array}$ & $\begin{array}{c}\text { D } \\
\text { D } \\
\text { E/F }\end{array}$ & \begin{tabular}{|c} 
D \\
D \\
E/F
\end{tabular} & \begin{tabular}{|c|}
$\mathbf{D}$ \\
$\mathbf{D}$ \\
$\mathbf{E} / \mathbf{F}$
\end{tabular} & $\begin{array}{c}\text { D } \\
\text { D } \\
\text { E/F }\end{array}$ \\
\hline
\end{tabular}

$\mathrm{WQ}=$ water quality, $\mathrm{RC}=$ Reference Condition, $\mathrm{PES}=$ Present Ecological State

Table 2 shows the percentage deviation of TDS from the reference condition for the present ecological state, and the predicted deviation under the recommended flow regime for the Pienaars River in WQ1. Despite the fact that the lowest TDS concentrations are predicted to occur during summer under both the maintenance and drought recommended flow regimes, the extent of deviation from the reference condition was found to be highest during this period. This is a consequence of the naturally very low salt levels expected in the river at this time of the year (Table 1).

viii) The predicted assessment category for each month, for each water quality variable, and for each recommended flow scenario was then assigned.

The assessment category (A to F) that each chemical constituent would fall into was then derived for each month under maintenance low flow and drought low flow. In addition, the mean category for the entire year was also calculated. The predicted assessment categories for TDS in Table 2 were derived using the percentage deviation from the reference condition as described in DWAF (1999). It can be seen from Table 2, that under the required maintenance low flow, TDS concentration would remain in an overall "D" class and would be more or less the same as at present (except for December and March). Under the recommended drought low flow, however, there would be a notable decrease in water quality (to an $\mathrm{E} / \mathrm{F}$ class)

\section{Discussion}

\section{General comments}

Flow-concentration modelling is a simple approach in that it is based on solute rating curves, a technique that has been used extensively in the literature (Gregory and Walling, 1973; Kronvang, 1992; Smith et al., 1996; Malan and Day, 2002b). Many factors, apart from flow, influence water quality, however, and these are not taken directly into account in this modelling method. Instream concentrations of chemical constituents resulting from a given discharge can vary depending on (inter alia) season, antecedent rainfall, land-use, temperature, and the operation of upstream impoundments (McDiffett et al., 1989; Britton et al., 1993; Davis and Keller, 1983; Petts, 1989). Thus Q-C modelling is aimed at providing an estimate of predicted water quality and whether the stipulated allowed maximum concentrations of each chemical constituent (i.e. the assessment category) will be exceeded under the recommended flow regime. Furthermore, water quality and pollution are complex, involving the interaction of many variables, which in turn affect the aquatic biota.

The Q-C modelling method has been developed into an integral component of ecological Reserve determinations (at the Intermediate, or Comprehensive level). Thus the first two steps and some of step iii) would automatically be carried out as part of the water quality assessment. It is envisaged that preparation of the Q-C plots would be carried out prior to the Instream Flow Requirement (IFR) Workshop. At the workshop, the specialists would first specify a flow regime that is designed to keep the river in a predefined ecological Reserve class. The model would then be used to predict the monthly concentrations of each water quality variable (referred to as the "water quality consequences"). It can thus be used as a screening tool to identify sites at which the water quality Reserve is not likely to be attained without amelioration of pollution sources. At such sites, a more sophisticated water quality model may be required to investigate pollution sources, and the detailed mitigation measures required to improve water quality to an acceptable level. The method is compatible with the Building Block Methodology (King and Louw, 1998; King et al., 2000) and with DRIFT (Downstream Response to Instream Flow Transformations) a newly emerging methodology for assessing environmental flow requirements in South Africa (King et al., in press).

Flow-concentration modelling is most useful for TDS, individual salts and ions and other conservative constituents, but is not suitable for simulation of dissolved oxygen or temperature. Nutrients, often exhibit considerable scatter when concentration is plotted against discharge, a likely consequence of the various processes (e.g. microbial conversion between chemical forms, ad- 
sorption/desorption from sediment particles, uptake by the biota) that influence instream concentration. In such cases the Q-C regression approach as it now stands cannot be used, but could be enhanced to include more complex multivariate regression approaches as required for a particular application.

The discharge regime recommended by river specialists at the IFR Workshop is for low flows, freshes and floods, and these are specified for both normal and drought hydrological conditions. In the case of the low flows, this represents the minimum volume of water required in the system to maintain the prerequisite state. Frequently, higher discharges would be present in the system as a result of recommended floods or freshes, or as a result of additional flow (i.e. water not required for abstraction or impoundment). The predicted concentrations in the case of water quality constituents that exhibit a dilution effect with increased flow therefore represent the worst-case scenario. Some constituents at some sites (notably TDS in salinised catchments of the Western Cape, and occasionally nitrates and phosphates in various parts of the country) have been found to increase with discharge (Malan and Day, 2002a). It is considered that the Q-C method may not always be suitable for making predictions of water quality in such situations. A positive concentration-flow relationship is often due to wash-off from the soils of the surrounding catchment. If streamflow is reduced in such systems (e.g. by in-channel abstraction), the loading of chemicals from wash-off will remain the same, and thus it cannot be assumed that instream concentrations will decrease (since the dilution capacity of the river is reduced). Predictions of instream concentration of such a constituent, under changed discharge conditions, will depend on how the flow change is brought about. Such situations are complex and accurate predictions of diffuse sources of pollutants are more difficult to make than for point sources. Further work is required to examine the use of the modelling method in situations where concentration is positively correlated with flow.

\section{Assumptions and limitations in the approach}

The major limitations and assumptions in the modelling approach are described below:

- A key limitation is that the user must have a good understanding of the hydrology, water quality data and general insight into the main processes influencing instream concentrations of chemical constituents in the river. Additional monitoring of water quality may be required at some sites if these fundamental processes are not fully understood.

- Use is made of monthly median values of concentrations and monthly average flow, through which a trend-line is fitted. Median and mean values are used for concentration and flow data, since this is the convention in the field of water quality and hydrology respectively. An alternative approach would be to use all data points for concentration linked to the discharge at the time of sampling. In this study, comparisons were made of the trend patterns and the value of the correlation coefficient obtained between measured and predicted data using either all data points or monthly data. It was found that Q-C trends could be more clearly discerned using monthly data, than if all data points were used. This is substantiated by the work of Pionke and Nicks (1970) who found that several widely divergent salinity values corresponded to the same discharge on an instantaneously determined basis whereas averaging the data on a monthly basis removed much of the variability.

- Because of the low frequency of occurrence of extremes of flow (either very low or very high) there are often few data for these regions. Thus extrapolation to these regions when making predictions of concentration is likely to be inaccurate.

- The modelling method is severely constrained by the availability of data. The degree of confidence in the predictions is influenced by the accuracy, and completeness, of the data that are used. If no suitable data are available, or if a poor correlation between concentration and flow is obtained, accurate predictions of instream concentration cannot be made. The accuracy of the predictions is also influenced by how representative the available water quality data are of the site, or water quality reach that is to be modelled. The greater the distance between the site and the monitoring station, or if a major tributary or other hydrological feature (e.g. a weir) is situated between the monitoring station and the IFR site, the less it can be assumed that the water quality predictions are representative. Field monitoring can be carried out to assess longitudinal gradients from the monitoring point to the site or reach under consideration.

- It is assumed that if flow is altered, apart from the concentration of the water quality variable under concern, all other parameters (e.g. the pollution load) will remain constant. In practice, if discharge is altered drastically it is likely that the source of the water, and hence the pollution loading will be altered (for example by means of impoundment of tributaries). In addition, changes in the operation of upstream impoundments may also be involved. This method is empirical in that it does not take into account changes in water quality management scenarios (i.e. changes in the loading of pollutants). It assumes that the relationship linking concentration and flow remains the same. Alterations to the system such as mentioned above are likely to change that relationship, making predictions using the original flowconcentration model inaccurate. This is a major limitation in the method and should be understood when making predictions of future water quality. At the moment there is usually no consideration of different water quality management scenarios in Reserve assessments in any case. This is a deficiency, which needs to be addressed. Should consideration of different scenarios be included, a more sophisticated form of water quality modelling, such as mass-balance modelling would most likely need to be employed at some sites.

- The method makes use of the standard regression functions available in commercial spreadsheet packages. Considering the inaccuracy inherent in the modelling method, it is considered that this simplification will not detract from the overall accuracy of the results.

\section{Information that can be obtained using flow- concentration modelling}

Using flow-concentration modelling, depending on the availability and reliability of data for each site or water quality reach, the following information can be obtained:

- Flow-concentration relationships and confidence intervals can be derived for key water quality constituents.

- Estimates can be made as to how many months of the year, under the proposed flow regime, the water quality Reserve will be attained with regard to the various water quality constituents (TDS, nutrients) and the likely assessment category (A, B, C etc.).

- In what month the worst water quality would be likely to occur and what concentrations could be expected.

- An estimate of the extent to which the predicted water quality will be different from natural.

- What discharge in the absence of pollution control, would be required to dilute pollutants to acceptable levels. 
- In the case of "natural water quality problems," what flows would be needed to dilute the chemical constituents in order to attain the water quality component of the Reserve.

\section{When flow-concentration modelling should not be used}

Predictions of water quality should not be made using Q-C modelling:

- If the available present-day water quality data do not satisfy the requirements as laid out in the Manual for Resource Directed Measures (DWAF, 1999). In the absence of data characteristic of the reference condition, predictions of future water quality can still be made, but the extent of deviation from natural cannot be assessed.

- If the nearest water quality monitoring station is in a different water quality reach from the site for which predictions are to be made. In other words, if no data are available that are considered to be representative of the water quality at the site, modelling should not be carried out.

- If accurate present-day flow data for the water quality reach under consideration are not available.

- If the value of $r^{2}$ for the present ecological state is low, the simulations should be discarded. An arbitrary value of $r^{2}=0.6$ has been chosen (for 10 degrees of freedom, $\alpha(2), p>0.003$ ) for the cut-off point. Below a value of $\mathrm{r}^{2}=0.6$, it can be concluded in such cases that factors other than discharge are also influencing instream concentrations. Predictions of water quality in such cases should be made using a more sophisticated water quality model such as QUAL2E or a catchment runoff model.

- If the concentration of the water quality variable is positively correlated with flow. Factors controlling instream concentration in such situations are likely to be complex and need to be investigated carefully before assessing if Q-C modelling can be used to make predictions of instream concentrations.

\section{Water quality and Reserve assessments}

An important principle within both the Building Block Methodology and DRIFT is that the environmental flows recommended should be those that satisfy the requirements of the aquatic biota with regard to hydraulic habitat. Flows should not be recommended because they are required to dilute contaminants to a level acceptable to the biota. If they are, it should be stated clearly that the "extra" water required for dilution is not part of the ecological Reserve. Yet, many South African rivers are impacted due to high levels of contaminants and if pollution sources are not addressed and implementation of environmental flows leads to a reduction in low flows, deterioration of water quality will result. The current approach therefore is to predict the likely water quality consequences of the recommended flow regime in the absence of pollution control (Palmer and Rossouw, 2001). In the context of environmental flow assessments it is important to distinguish between "anthropogenic " water quality problems as mentioned above and "natural" water quality problems. The latter would include instances where for example, due to the geology of the surrounding catchment, water draining that region is naturally saline, resulting in elevated concentrations in the river. The aquatic biota in such reaches are adapted to high salinity levels. Implementation of a flow regime, however, for which the maintenance and drought flows represent a reduced discharge volume may well result in unacceptably high levels of inorganic salts. In such a case, adjustment of the water quantity Reserve to attain the water quality aspect of the Reserve is justified.

\section{Conclusion}

Flow-concentration modelling represents a pragmatic method for assessing the likely water quality conditions that will arise from implementation of a recommended flow regime. It is recognised that the method is simplistic and can only be used to give estimates of predicted concentrations of chemical constituents, however, it does give some insight into the likely duration and frequency of water quality that may be stressful to aquatic biota. The major limitation of the method is that it does not take into account different sources and loading of contaminants. This deficiency is not restricted to the modelling method in that this is a major limitation in the Reserve determination process at the moment. As long as the assumptions and limitations in the method are understood, however, Q-C modelling can be useful as a screening tool to identify sites where, without reduction of pollution loading, the water quality component of the Reserve is unlikely to be attained under the recommended flow regime.

\section{Acknowledgements}

The Water Research Commission is gratefully acknowledged for funding the project in which this work was carried out. We would also like to thank the members of DWAF who tirelessly collect, collate and distribute the hydrological and water quality data from our rivers, without which this study would not be possible.

\section{References}

BRITTON DL, DAY JA and HENSHALL-HOWARD M-P (1993) Hydrochemical response during storm events in a South African mountain catchment: The influence of antecedent conditions. Hydrobiol. 250 143-157.

DALLAS HF and DAY JA (1993) The Effect of Water Quality Variables on Riverine Ecosystems: A Review. WRC Report No TT 61/93, Water Research Commission, Pretoria.

DAVIS JS AND KELLER HM (1983) Dissolved loads in streams and rivers - Discharge and seasonally related variations. In: Proc. Hamburg Symp. on Dissolved Loads in Streams and Rivers Discharge and Seasonally Related Variations. August 1983. IAHS Publication no. 141. 79-89.

DWAF (1999) Resource Directed Measures for Protection of Water Resources. Institute for Water Quality Studies, Department of Water Affairs and Forestry, Pretoria.

DWAF (2002) Methods for Assessing Water Quality in Ecological Reserve Determinations for rivers. Department of Water Affairs and Forestry, Pretoria. Draft document.

GREGORY KJ and WALLING DE (1973) Drainage Basin Form and Process: A Geomorphological Approach. John Wiley and Sons, New York.

HUGHES DA (1999) Towards the incorporation of magnitudefrequency concepts into the Building Block Methodology used for quantifying ecological flow requirements of South African rivers. Water SA 25 (3) 279-284.

HUGHES DA (2001) Providing hydrological information and data analysis tools for the determination of the ecological instream flow requirements for South African rivers. J. Hydrol. 241 (1-2) 140-151.

KING J, BROWN C and SABET H (in press) A scenario-based holistic approach to environmental flow assessments for regulated rivers. River Res. Applic.

KING J and LOUW D (1998) Instream flow assessments for regulated rivers in South Africa using the Building Block Methodology. Aquat. Ecosyst. Health Manage. 1 109-124.

KING JM, THARME RE and DE VILLIERS MS (2000) Environmental flow assessments for rivers: Manual for the Building Block Meth- 
odology. WRC Report No TT 131/00, Water Research Commission, Pretoria.

KRONVANG B (1992) The export of particulate matter, particulate phosphorus and dissolved phosphorus from two agricultural river basins: Implications on estimating the non-point phosphorus load. Water Res. 26 1347-1358.

LOUW D, HUGHES D and BIRKHEAD A (2000) The IFR process: beyond the specialist workshop. Afr. J. Aquat. Sci. 25 183-190.

MALAN HL (2001) Integration of water quality and quantity (water quality modelling). In: Palmer C and Rossouw JN (ed.)Water Quality: Olifants River Ecological Water Requirement Assessment. Appendix 7. Department of Water Affairs and Forestry, Report No. PB 000-00-5999. Pretoria. 7/1-7/33.

MALAN HL and DAY JA (2002a) Development of Numerical Methods for Predicting Relationships between Streamflow, Water Quality and Biotic Responses in Rivers. WRC Report No. 956/1/ 02, Water Research Commission, Pretoria.

MALAN HL and DAY JA (2002b) Linking Discharge, Water Quality and Biotic Response in Rivers: A Literature Review. WRC Report No. 956/2/02, Water Research Commission, Pretoria.

McDIFFETT WF, BEIDLER AW, DOMINICK TF and McCREA KD (1989) Nutrient concentration-stream discharge relationships during storm events in a first-order stream. Hydrobiol. 179 97-102.

PALMER C and ROSSOUW JN (2001) Water Quality: Olifants River Ecological Water Requirement Assessment. Department of Water Affairs and Forestry Report no. PB 000-00-5999, Pretoria.

PETTS GE (1989) Perspectives for ecological management of regulated rivers. In: Gore JA and Petts GE (eds.) Alternatives in Regulated River Management. CRC Press, Inc, Boca Raton, Florida. 3-24.

PIONKE HB and NICKS AD (1970) The effect of selected hydrologic variables on stream salinity. Bull. Int. Assoc. Sci. Hydrol. 15 13-21.

ROSSOUW JN, HOHLS B AND JOOSTE S (1999) Water Quality Report, Pienaars River Intermediate Reserve Determination. Unpublished report for RDM office, Department of Water Affairs and Forestry, Pretoria.

SMITH DG, MCBRIDE GB, BRYERS GG, WISSE J and MINK DFJ (1996) Trends in New Zealand's national river water quality network. N. Z. J. Mar. \& Freshwater Res. 30 485-500.

UNDERHILL LG (1985) Introstat. Juta and Company, Ltd., Kenwyn, South Africa. 
